\title{
Berberine inhibits cyclin D1 expression via suppressed binding of AP-1 tran- scription factors to CCND1 AP-1 motif ${ }^{1}$
}

\author{
Ye $\mathrm{LUO}^{2,3}$, Yu HAO ${ }^{2,4}$, Tai-ping $\mathrm{SHI}^{3}$, Wei-wei DENG ${ }^{3}, \mathrm{Na} \mathrm{LI}^{3}$ \\ ${ }^{2}$ Department of Immunology, School of Basic Medical Science, Beijing University of Chinese Medicine, Beijing 100029, China; ${ }^{3}$ Chinese \\ National Human Genome Center, Beijing 100176, China
}

\section{Key words}

transcription factors; activating protein-1; berberine; cell cycle; cyclin D1

${ }^{1}$ Project supported by the National High Technology Research and Development Program of China (863 Program; No 2006AA02A305).

${ }^{4}$ Correspondence to Prof $\mathrm{Yu}$ HAO.

Phn 86-10-6428-6973.

E-mailyuhao64@sina.com.cn

Received 2007-12-12

Accepted 2008-01-30

doi: $10.1111 / \mathrm{j} .1745-7254.2008 .00786 . x$

\begin{abstract}
Aim: To verify the suppressive effect of berberine on the proliferation of the human pulmonary giant cell carcinoma cell line PG and to demonstrate the mechanisms behind the antitumoral effects of berberine. Methods: The proliferative effects of PG cells were detected by 3-(4,5-dimethylthiazol-2-yl)-2,5diphenyltetrazolium bromide colorimetry. The cell cycle was examined by flow cytometry. The expression level of cyclin D1 was detected by RT-PCR. The activities of the activating protein-1 (AP-1) and NF- $\mathrm{\kappa B}$ signaling pathways related to cyclin D1 were examined by luciferase assay. The cytoplasmic level of c-Jun was detected by Western blot analysis. An electrophoretic mobility shift assay was used to examine the binding of transcription factors to the cyclin D1 gene (CCND1) AP-1 motif. Results: The results showed that the proliferation of PG cells treated with different concentrations $(10,20$, and $40 \mu \mathrm{g} / \mathrm{mL})$ of berberine for 24 and $48 \mathrm{~h}$ was suppressed significantly compared to the control group. After treatment with berberine, the proportion of $P G$ cells at the $G_{0} / G_{1}$ phase increased, while cells at the $S$ and $\mathrm{G}_{2} / \mathrm{M}$ phases decreased. Berberine could inhibit the expression of cyclin D1 in PG cells. Berberine inhibited the activity of the AP-1 signaling pathway, but had no significant effect on the NF- $\kappa B$ signaling pathway. Berberine suppressed the expression of c-Jun and decreased the binding of transcription factors to the CCND1 AP-1 motif. Conclusion: Berberine suppresses the activity of the AP-1 signaling pathway and decreases the binding of transcription factors to the CCNDI AP-1 motif. This is one of the important mechanisms behind the antitumoral effects of berberine as a regulator of cyclin D1.
\end{abstract}

\section{Introduction}

Berberine is an isoquinoline derivative alkaloid isolated from many medicinal herbs, such as Rhizoma coptidis and Cortex phellodendri. It is widely used in traditional Chinese medicine for antimicrobial and anti-inflammatory activities. In recent years, berberine has been reported to have a wide range of pharmacological effects, including immunological regulation ${ }^{[1]}$, myocardial protection ${ }^{[2]}$, inhibition of tumor cell proliferation ${ }^{[3]}$, and invasion ${ }^{[4]}$. Recently, we reported the inhibitory effect of berberine on the invasion and migration of lung carcinoma cells $\mathrm{s}^{[5]}$.

Cyclin D1 is a member of the $G_{1}$ cyclin family involved in the regulation of the $\mathrm{G}_{1} / S$ transition of the cell cycle ${ }^{[6]}$. The cyclin D1/cyclin-dependent kinase 4 (CDK4) complex can hyperphosphorylate retinoblastoma tumor suppressor protein $1(\mathrm{Rb} 1)^{[7]}$, leading to the dissociation of E2 promoter-binding protein dimerization partners (E2F) from the Rb1/E2F complex $^{[8]}$. Dissociated E2F induces the transcription of cyclin $\mathrm{E}$ and other genes required for entry into the $S$ phase. Cyclin D1 is frequently overexpressed in a wide range of cancers. The nuclear accumulation of cyclin D1 induces uncontrolled proliferation in normal human cells, which may facilitate the development of invasive cancer ${ }^{[9]}$. The cyclin D1 expression is under complex regulation and is markedly influenced by the activating protein-1 (AP-1), NF- $\kappa \mathrm{B}$, and $\beta$-catenin/T cell factor (TCF) signaling pathways ${ }^{[10-12]}$. A number of compounds 
targeting these signaling pathways can indirectly attenuate the cyclin D1 expression to mediate cell cycle arrest.

AP-1 is a sequence-specific transcription factor composed of homodimers or heterodimers of the Jun family (cJun, Jun D, and Jun B) or heterodimers of the Jun family members with any of the Fos family members (c-Fos, Fos B, Fra1, and Fra2). AP-1 has long been associated with proliferation. AP-1 directs the expression of a critical target gene or genes, such as the cyclin D1 gene, in response to cytokines, stress, and mitogenic signals ${ }^{[13]}$. The promoter for $C C N D 1$ (encoding cyclin D1) contains an AP-1 motif, and the ectopic expression of c-Jun induces the cyclin D1 mRNA expression ${ }^{[14]}$.

The present study was performed to verify the suppressive effect of berberine on the proliferation of the human pulmonary giant cell carcinoma cell line $\mathrm{PG}$ and demonstrate the mechanisms behind the antitumoral effects of berberine.

\section{Materials and methods}

Cell culture Human pulmonary giant cell carcinoma cell line PG (Peking University Medical Center, Beijing, China ${ }^{[15]}$ were cultivated in RPMI-1640 medium supplemented with $10 \%$ fetal bovine serum. Cell cultures were maintained in a $37{ }^{\circ} \mathrm{C}$ incubator under a humidified $5 \% \mathrm{CO}_{2}$ atmosphere, and were routinely subcultured by trypsinization. All experiments were performed on logarithmically-growing cells.

Cell proliferation/viability assay The $\mathrm{PG}$ cells were seeded onto 96-well culture plates and incubated for $24 \mathrm{~h}$ at $37^{\circ} \mathrm{C}$ and then treated with berberine $(10,20$, and $40 \mu \mathrm{g} / \mathrm{mL}$; NICPBP, Beijing, China) or without. After 24 or $48 \mathrm{~h}$, cell proliferation was assayed by using a 3-(4,5-dimethylthiazol-2-yl)-2,5diphenyltetrazoliumbromide (MTT) kit (Promega, Madison, WI, USA). The absorbance was recorded with a microplate reader (model 550, Bio-Rad, Hercules, CA, USA); viability was determined as $(\%)=\left(A_{570}-A_{630}\right)$ sample $/\left(A_{570}-A_{630}\right)$ control $\times 100 \%$.

Cell cycle analysis The PG cells were treated with berberine $(0,20$, and $40 \mu \mathrm{g} / \mathrm{mL})$ for $48 \mathrm{~h}$. The cells were then harvested, washed with cold phosphate-buffered saline (PBS), and processed for cell cycle analysis. Briefly, $2 \times 10^{5}$ cells were resuspended in $0.5 \mathrm{~mL}$ cold PBS, to which cold ethanol $(70 \%, 5 \mathrm{~mL})$ was added; the cells were then incubated for $1 \mathrm{~h}$ at $4{ }^{\circ} \mathrm{C}$. After centrifugation, the pellet was washed with cold PBS, suspended in $0.3 \mathrm{~mL}$ PBS, and incubated with $50 \mu \mathrm{L}$ RNase $(1 \mathrm{mg} / \mathrm{mL})$ for $30 \mathrm{~min}$ at $37^{\circ} \mathrm{C}$. The cells were kept on ice for $10 \mathrm{~min}$ and incubated with $500 \mu \mathrm{L}$ propidium iodide $(50 \mathrm{mg} / \mathrm{L})$ for $30 \mathrm{~min}$ in the dark. The cell cycle distribution of the cells of each sample was then determined by using a FACSCalibur instrument (BD Biosciences, San Jose, CA, USA) equipped with FACSort Cell Quest software.
RT-PCR After treatment with or without berberine, total RNA was extracted. Three micrograms of total RNA was reverse transcribed using SuperScript III reverse transcriptase (Invitrogen, Carlsbad, CA, USA) at $50{ }^{\circ} \mathrm{C}$ for $2 \mathrm{~h}$. The $20 \mu \mathrm{L}$ PCR reaction contained $2 \mu \mathrm{L}$ of $10 \times$ Taq buffer, $0.5 \mu \mathrm{L}$ of each primer $10 \mu \mathrm{mol} / \mathrm{L}$; cyclin D1: 5'-GCG AGG AAC AGA AGT GCG-3' [sense] and 5'-GAA GCG TGT GAG GCG GTA-3' [antisense], and GAPDH: 5'GGGGAAGGT GAAGGTCGG3' [sense] and 5'-ATG AGT CCT TCC ACG ATA CCA A-3' [antisense], 0.2 $\mu \mathrm{L}$ Taq DNA polymerase (Tiangen, Beijing, China), $0.5 \mu \mathrm{L}$ of $10 \mathrm{mmol} / \mathrm{L} \mathrm{dNTP}$, and $1 \mu \mathrm{L} \mathrm{cDNA}$. GAPDH was used as an internal loading control. The expected sizes of the PCR products for cyclin D1 and GAPDH were 494 and 522 bp, respectively.

Cell transfection and luciferase assay The PG cells were seeded onto 96-well plates and incubated for $24 \mathrm{~h}$ at $37^{\circ} \mathrm{C}$.

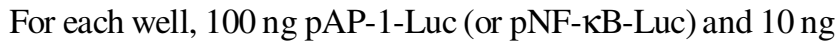
pRL-TK (Promega, USA) were mixed and cotransfected using the calcium phosphate precipitation method according to standard protocols ${ }^{[16]}$.

The cells were treated with the indicated concentrations of berberine for $6 \mathrm{~h}$ after transfection, and incubated for an additional $24 \mathrm{~h}$. The stimulus group was treated with phorbol myristate acetate (PMA and ionomycin $(\mathrm{P}+\mathrm{I})$ for $6 \mathrm{~h}$ before being lysed. The cells were then lysed in $40 \mu \mathrm{L}$ of passive lysis buffer (Promega, USA). Firefly luciferase and Renilla luciferase activities were measured with $10 \mu \mathrm{L}$ cell lysate using the Dual luciferase reporter assay system (Promega, USA) in a GENios pro reader (Tecan, Hombrechtikon, Switzerland). Relative activity was defined as the ratio of firefly luciferase activity to Renilla luciferase activity and was calculated by dividing the luminescence intensity obtained in the assay for firefly luciferase by that obtained for Renilla luciferase.

Western blot analysis After the berberine treatments, the PG cells were harvested, and whole-cell lysates were prepared. Equal amounts of protein samples were separated by SDS-PAGE gel and blotted onto nitrocellulose (NC) membrane (Millipore, Bedford, MA, USA). After blocking, the membranes were incubated at $4{ }^{\circ} \mathrm{C}$ with antibodies against cJun (1:500) or cyclin D1 (1:200; Santa Cruz Biotechnologies, Santa Cruz, CA, USA). $\beta$-Actin was used as an internal loading control. The blots were then washed and incubated for $1 \mathrm{~h}$ with horseradish peroxidase-labeled secondary antibody (1:4000; Zhongshan Golden Bridge, Beijing, China). Immunoreactive bands were visualized with a SuperSignal West Pico chemiluminescnet kit (Pierce, Rockford, IL, USA).

Electrophoretic mobility shift assay Nuclear extracts were prepared by using a NE-PER nuclear and cytoplasmic extrac- 
tion reagent kit (Pierce, USA) according to standard protocols. The CCND1 AP-1 site, the wild-type collagenase AP-1 site, and a mutant $C C N D 1$ AP-1 site were synthesized as complementary oligodeoxyribonucleotide strands. The sequence of the $C C N D 1$ promoter AP-1 site oligodeoxyribonucleotides was 5'-TCC ATT CTG ACT CAT TTT TTT TAA-3', and the sequence of the mutant AP-1 site was 5'-TCC ATT CTG cCg CAT TTT TTT TAA-3'. The sequence of the wild-type collagenase AP-1 oligodeoxyribonucleotides was 5'-CGC TTG ATG AGT CAG CCG GAA-3 ${ }^{-[17]}$.

The DNA binding ability of AP-1 in the nuclear extracts was assessed by electrophoretic mobility shift assay (EMSA) ${ }^{[18]}$ with biotin-labeled, double-stranded, wild-type collagenase AP-1 oligonucleotides and CCND1 AP-1 oligonucleotides. EMSA was carried out by using the Lightshift chemiluminescent EMSA kit (Pierce, USA). Specific binding was confirmed by using a 250-fold excess of an unlabeled probe as a specific competitor. Protein-DNA complexes were separated by using a $6 \%$ non-denaturing acrylamide gel electrophoresis and then transferred to positively-charged nylon membranes and cross-linked by UV irradiation. Gel shifts were visualized with streptavidin horseradish peroxidase according to standard protocols.

Statistical analysis All data are expressed as mean \pm SD. Student's unpaired $t$-test was used to compare differences between 2 groups. Figures were obtained from at least 3 independent experiments with similar patterns.

\section{Results}

Berberine inhibits the proliferation and viability of PG cells The PG cells were treated with $0,10,20$, and $40 \mu \mathrm{g} / \mathrm{mL}$ berberine for 24 and $48 \mathrm{~h}$. The treatment of the PG cells with berberine $(10-40 \mu \mathrm{g} / \mathrm{mL})$ resulted in a significant reduction in cell proliferation/viability as assessed by MTT assay, ranging from $27 \%$ to $36 \%(P<0.01)$ after $24 \mathrm{~h}$, and $63 \%$ to $73 \%(P<0.01)$ after $48 \mathrm{~h}$ (Figure $1 \mathrm{~A})$.
A

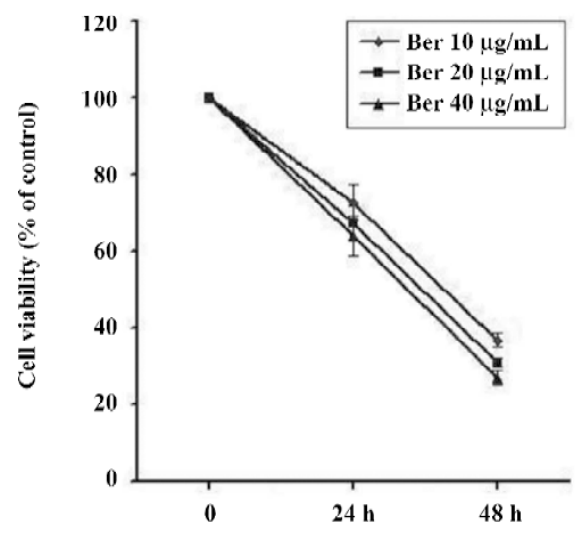

C

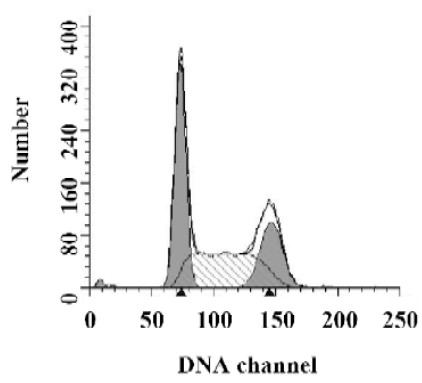

B
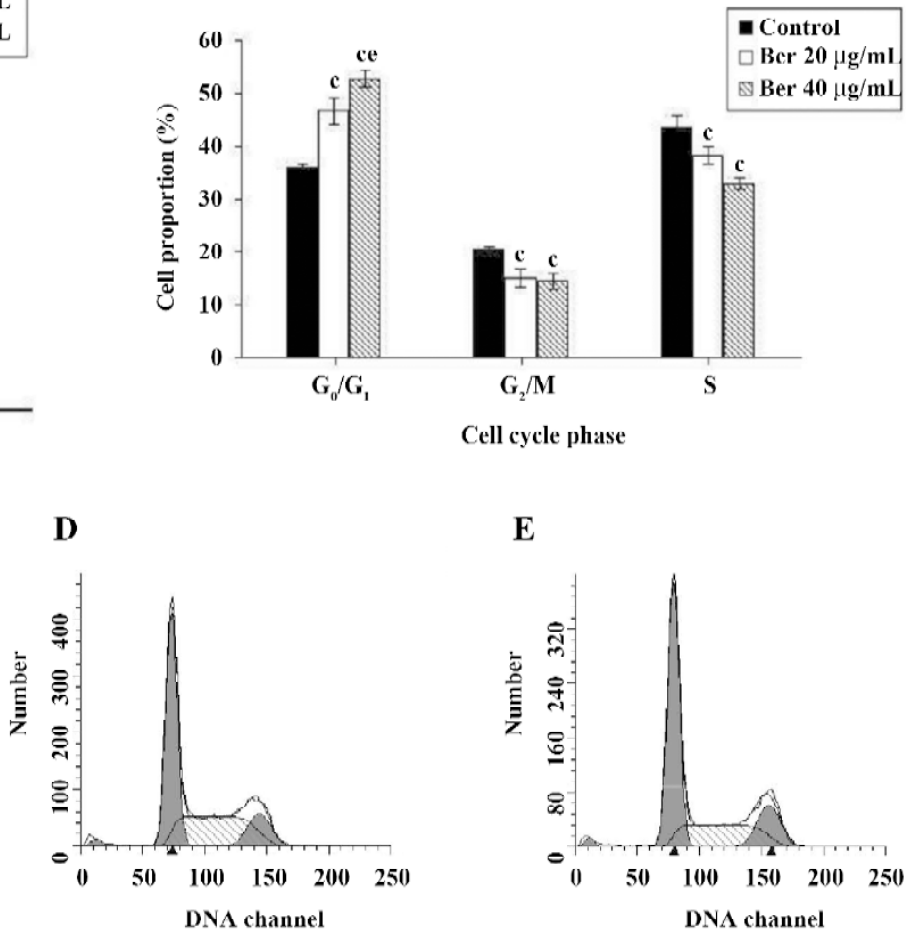

$\mathbf{E}$

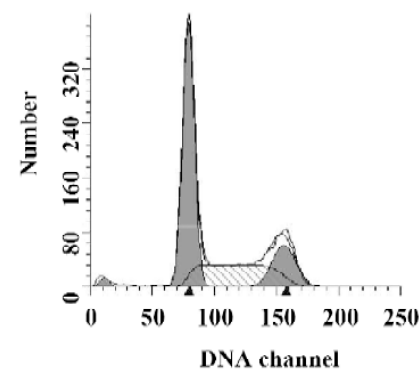

Figure 1. Effect of berberine on the proliferation and cell cycle progression of PG cells. (A) cell proliferation was determined by using the MTT assay. Time course shows the inhibition of berberine on PG cell proliferation (percentage of control) at 24 and $48 \mathrm{~h}$. $n=5$. Data are presented as mean $\pm \mathrm{SD}$. (B) PG cells were cultured in complete medium and treated with 0,20 , or $40 \mu \mathrm{g} / \mathrm{mL}$ berberine. After $48 \mathrm{~h}$ of treatment, cells were harvested, washed with cold PBS buffer, and digested with RNase. Cellular DNA was stained with propidium iodide (PI) and flow cytometric analysis was applied to determine the cell cycle distribution. $n=3$. Data are presented as mean \pm SD. ${ }^{c} P<0.01 v s$ control. ${ }^{e} P<0.05 v s$ low-berberine-treated group. (C-E) cell cycle phase detected by flow cytometry. PG cells treated with berberine at $0 \mu \mathrm{g} / \mathrm{mL}$ (C), $20 \mu \mathrm{g} / \mathrm{mL}$ (D), and $40 \mu \mathrm{g} / \mathrm{mL}$ (E). 


\section{Berberine induces $G_{1}$ phase cell cycle arrest in PG cells} As we found a significant growth inhibitory effect of berberine on PG cells, we determined the possible inhibitory effect of berberine on cell cycle progression. The treatment of PG cells with berberine ( 20 and $40 \mu \mathrm{g} / \mathrm{mL}$ ) for $48 \mathrm{~h}$ resulted in a significantly higher number of cells in the $G_{1}$ phase at the concentrations used: $20 \mu \mathrm{g} / \mathrm{mL}(47 \%, P<0.01)$ and $40 \mu \mathrm{g} / \mathrm{mL}$ (53\%, $P<0.01)$, compared with the non-berberine-treated control (36\%; Figure 1B). In each case, there was a concomitant reduction in the number of cells in the $S$ and $G_{2}-M$ phases. These data suggested that the inhibition of cell proliferation in PG cells by berberine may be associated with the induction of $\mathrm{G}_{1}$ arrest.

Berberine suppresses the cyclin D1 expression Based on the preliminary assays in which we determined the effects of berberine on cell proliferation and viability, in order to minimize the cytotoxic effect of berberine, we selected doses lower than $10 \mu \mathrm{g} / \mathrm{mL}$ for further mechanism studies.

Cyclin D1 is a downstream molecule regulated by the AP-1 and NF- $\mathrm{KB}$ signaling pathways, and is a key molecule that controls the cell cycle entry from the $G_{1}$ phase to the $S$ phase. We applied RT-PCR and immunoblotting to check the mRNA and protein expressions of cyclin D1. Treatment with berberine at different concentrations significantly downregulated the cyclin D1 mRNA and protein expressions (Figure 2).

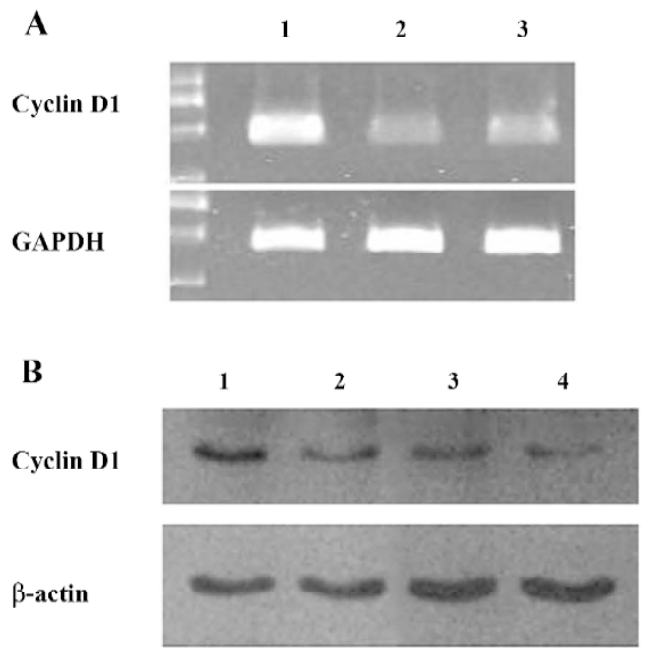

Figure 2. Effect of berberine on the expression of cyclin D1 in PG cells. (A) PG cells were treated with or without berberine. Total RNA was then isolated for the analysis of cyclin D1. Levels of mRNA were determined by RT-PCR. Lanes $1-3,0,2.5$, and $5 \mu \mathrm{g} / \mathrm{mL}$ berberine treated for $24 \mathrm{~h}$. GAPDH was used as an internal loading control. (B) PG cells were treated with or without berberine or not. Wholecell lysates were then prepared and subjected to SDS-PAGE followed by Western blotting with anti-cyclin D1 antibodies. Lanes 1-4, 0, 2.5, 5 , and $10 \mu \mathrm{g} / \mathrm{mL}$ berberine treated for $24 \mathrm{~h}$. $\beta$-Actin was used as an internal loading control.
Berberine inhibits AP-1 transcriptional activity $\mathrm{Lu}-$ ciferase activity in the cells with the AP-1 construct was significantly reduced by treatment with berberine at $2.5,5$, and $10 \mu \mathrm{g} / \mathrm{mL}$, whereas luciferase activity in the cells containing the NF- $\kappa \mathrm{B}$ construct showed no statistically significant changes in the presence of berberine (Figure 3A, 3B). After treatment with PMA $(60 \mathrm{ng} / \mathrm{mL})$ and ionomycin $(1.25$ $\mu \mathrm{mol} / \mathrm{L})$, the cells with the AP-1 construct showed a significant decrease in luciferase activity in the presence of berberine (Figure 3C). The results demonstrated that berberine could suppress the AP-1 pathway in PG cells, but had no significant effect on the NF- $\kappa \mathrm{B}$ pathway, Moreover, berberine significantly inhibited the AP-1 pathway when it was activated by the stimulus.
A

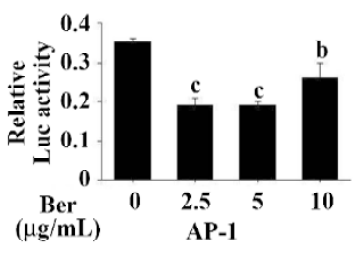

C

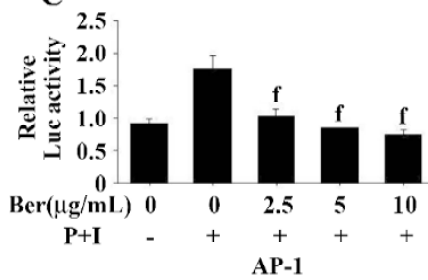

B

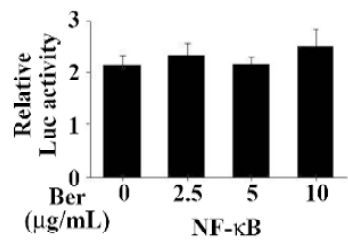

D

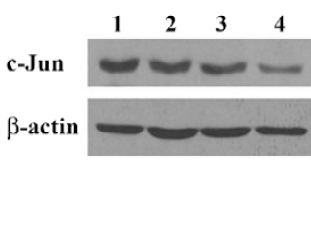

Figure 3. Effect of berberine on the activities of the AP-1 and NF$\mathrm{KB}$ signaling pathways in $\mathrm{PG}$ cells. $\mathrm{PG}$ cells were transfected with reporter vectors containing binding sites for AP-1 (A) or NF- $\mathrm{KB}$ (B), and cultured in the presence of berberine for $24 \mathrm{~h}$; luciferase activity was measured. $n=3$ independent experiments. Mean \pm SD. ${ }^{b} P<0.05$, ${ }^{\mathrm{c}} P<0.01 \mathrm{vs}$ control. (C) PG cells were transfected with reporter vectors containing binding sites for AP-1, and cultured in the presence of berberine for $24 \mathrm{~h}$. After the PG cells were treated with PMA and ionomycin for $6 \mathrm{~h}$, luciferase activity was measured. Columns represent the means of 3 independent experiments; bars represent the SD. ${ }^{\mathrm{f}} P<0.01 \mathrm{vs} \mathrm{P}+\mathrm{I}$ group without berberine treatment. (D) PG cells were treated with or without berberine. Whole-cell lysates were then prepared and subjected to SDS-PAGE followed by Western blotting with anti-c-Jun antibodies. Lanes $1-4,0,2.5,5$, and $10 \mu \mathrm{g} / \mathrm{mL}$ berberine treated for $24 \mathrm{~h}$. $\beta$-Actin was used as an internal loading control.

Berberine inhibits the c-Jun expression The luciferase assay results suggest that berberine inhibits the activity of the AP-1 pathway. c-Jun is primarily a positive regulator of cell proliferation ${ }^{[18]}$. The activated c-Jun-containing AP-1 complex induces the transcription of positive regulators of cell cycle progression, such as cyclin D1. We examined the effects of berberine on the expression of c-Jun by immunoblotting 
using the same culture and treatment conditions as before. Berberine treatment $(2.5,5$, and $10 \mu \mathrm{g} / \mathrm{mL})$ significantly decreased the expression of c-Jun (Figure 3D).

Berberine decreases transcription factors binding to the $C$ CND1 gene AP-1 motif To validate the previous results further, EMSA were performed by using oligonucleotides containing the wild-type collagenase AP-1 site as the probe. The PG cells were incubated in the presence of different concentrations of berberine for $24 \mathrm{~h}$, and nuclear extracts were then prepared and analyzed for AP-1 DNA binding activity. The results indicated that the activity of AP-1 decreased dramatically when the cells were treated with berberine (Figure 4A). These data were consistent with the reporter gene analysis. The binding of transcription factors to the CCND1 gene AP-1 motif was detected by using oligonucleotides containing the CCNDI AP-1 site as the probe.

A

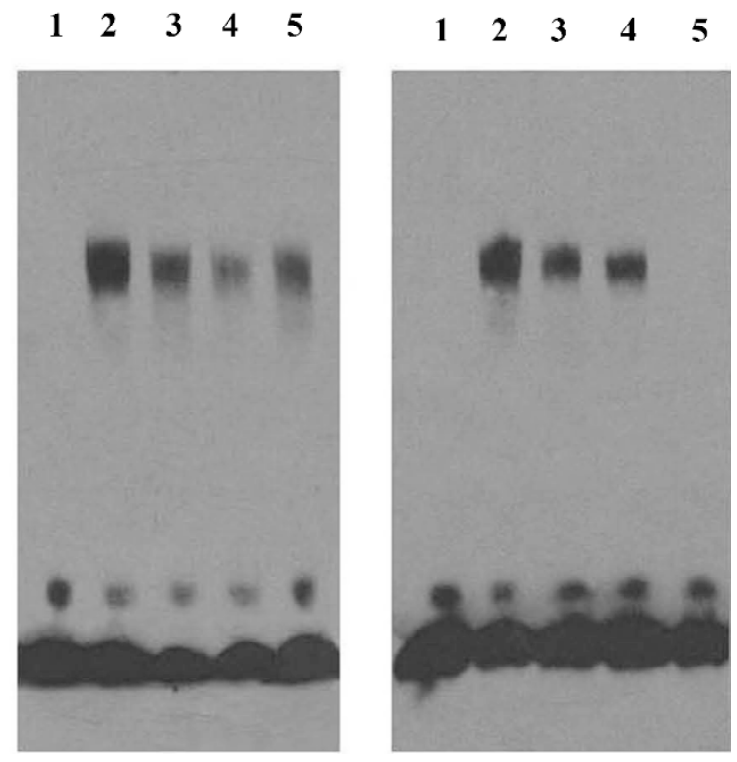

Figure 4. Effects of berberine on the DNA binding of AP-1. (A) nuclear extract prepared from the control or PG cells treated with berberine was mixed with biotin-labeled oligonucleotide containing wild-type AP-1 motif. Bound complexes were analyzed by electrophoresis. Lane 1 represents nuclear extracts incubated with 250 -fold unlabeled oligonucleotide (cold competitor) to confirm the specificity of binding. 2-5, 0, 2.5, 5, and $10 \mu \mathrm{g} / \mathrm{mL}$ berberine treated for $24 \mathrm{~h}$. (B) nuclear extract prepared from the control or PG cells treated with berberine for $24 \mathrm{~h}$ was mixed with biotin-labeled oligonucleotide containing the CCND1 AP-1 motif. Bound complexes were analyzed by electrophoresis. Lane 1, free; lane 2 and 3, 0 and $5 \mu \mathrm{g} / \mathrm{mL}$ berberine treated for $24 \mathrm{~h}$. Lane 4 represents nuclear extracts incubated with the 250 -fold mutant $C C N D 1$ AP-1 cold competitor. Lane 5 represents nuclear extracts incubated with the 250 -fold cold self-competitor. Excess-free probe is indicated at the bottom.
The binding decreased in the presence of berberine, while the mute probes had no effect on the combination (Figure 4B). The results suggested that berberine blocked the cyclin D1 expression, at least in part, by decreasing the expression or DNA binding activity of members of the AP-1 transcription factor family.

\section{Discussion}

Berberine is one of the major components of Coptis chinensis, which was frequently used in proprietary herbal medicines to treat inflammation in Europe and Asia. Berberine exhibits a broad spectrum of antimicrobial activity by inhibiting fungal, yeast, and bacterial proliferation with no toxicity. Studies have shown that berberine exerts a wide range of effects on angiogenesis ${ }^{[19]}$, cell proliferation, apoptosis $^{[20]}$, cell cycle ${ }^{[21]}$, and tumor metastasis in various in vivo and in vitro models. It is then valuable to investigate the mechanisms of such antitumoral effects of berberine.

The inhibitory effect of berberine on AP-1 activity has been reported previously ${ }^{[22,23]}$. However, the action mechanism of berberine on AP-1 remains unknown. The downstream target genes of AP-1, containing putative AP-1-binding sites in the promoters, are involved in many critical cellular functions, such as cell cycle progression and DNA synthesis ${ }^{[18]}$. CCND1 is a prototype of such a gene that may directly link AP-1 to cell cycle progression. Cyclin D1 antisense treatment blocks mammary tumor growth in vivo ${ }^{[24]}$, and cyclin D1 knockout mice are resistant to mammary tumor development by ras $^{[25,26]}$. In the present study, we demonstrated that berberine inhibits the expression of cyclin D1 by downregulating AP-1 transcriptional activity. Thus berberine arrests cell cycle progression and exerts antitumoral effects.

In summary, our results show that berberine significantly suppresses AP-1 transcriptional activity, leading to the inhibition of the cyclin D1 expression through the suppression of the c-Jun expression and binding of transcription factors to the $C C N D 1$ gene AP-1 motif. Berberine arrests cell cycle progression and proliferation of PG cells. These findings elucidate one of the important mechanisms behind the antitumoral effects of berberine as a regulator of cyclin D1.

\section{References}

$1 \mathrm{Xu} \mathrm{LH}$, Liu Y, He XH. Inhibitory effects of berberine on the activation and cell cycle progression of human peripheral lymphocytes. Cell Mol Immunol 2005; 2: 295-300.

2 Zhao HP, Hong Y, Xie JD, Xie XR, Wang J, Fan JB. Effect of berberine on left ventricular remodeling in renovascular hypertensive rats. Yao Xue Xue Bao 2007; 42: 336-41.

3 Letasiova S, Jantova S, Miko M, Ovadekova R, Horvathova M. 
Effect of berberine on proliferation, biosynthesis of macromolecules, cell cycle and induction of intercalation with DNA, dsDNA damage and apoptosis in Ehrlich ascites carcinoma cells. J Pharm Pharmacol 2006; 58: 263-70.

4 Peng PL, Hsieh YS, Wang CJ, Hsu JL, Chou FP. Inhibitory effect of berberine on the invasion of human lung cancer cells via decreased productions of urokinase-plasminogen activator and matrix metalloproteinase-2. Toxicol Appl Pharmacol 2006; 214 : 8-15.

5 Hao Y, Xu BW, Zheng H, Wang Q, Qiu QY, Huang QF. Effect of berberine on invasion and migration of PG cells from a high metastatic human giant lung carcinoma cell line. Chin J Pathophysiol 2007; 23: 474-8.

6 Matsushime H, Roussel MF, Ashmun RA, Sherr CJ. Colonystimulating factor 1 regulates novel cyclins during the $\mathrm{G} 1$ phase of the cell cycle. Cell 1991; 65: 701-13.

7 Kato JY, Matsuoka M, Strom DK, Sherr CJ. Regulation of cyclin D dependent kinase 4 (cdk4) by cdk4-activating kinase. Mol Cell Biol 1994; 14: 2713-21.

8 Kato J, Matsushime H, Hiebert SW, Ewen ME, Sherr CJ. Direct binding of cyclin $\mathrm{D}$ to the retinoblastoma gene product $(\mathrm{pRb})$ and pRb phosphorylation by the cyclin D-dependent kinase CDK4. Genes Dev 1993; 7: 331-42.

9 Gautschi O, Ratschiller D, Gugger M, Betticher DC, Heighway J. Cyclin D1 in non-small cell lung cancer: a key driver of malignant transformation. Lung Cancer 2007; 55: 1-14.

10 Eferl R, Wagner EF. AP-1: a double-edged sword in tumorigenesis. Nat Rev Cancer 2003; 3: 859-68.

11 Joyce D, Bouzahzah B, Fu M, Albanese C, D'Amico M, Steer J, et al. Integration of rac-dependent regulation of cyclin D1 transcription through a nuclear factor- $\kappa \mathrm{B}-$ dependent pathway. J Biol Chem 1999; 274: 25 245-9.

12 Natsume H, Sasaki S, Kitagawa M, Kashiwabara Y, Matsushita A, Nakano K, et al. $\beta$-Catenin/Tcf-1-mediated transactivation of cyclin D1 promoter is negatively regulated by thyroid hormone. Biochem Biophys Res Commun 2003; 309: 408-13.

13 Shaulian E, Karin M. AP-1 in cell proliferation and survival. Oncogene 2001; 20: 2390-400.

14 Fu M, Wang C, Zhang X, Pestell RG. Signal transduction inhibitors in cellular function. Methods Mol Biol 2004; 284: 15-36.

15 Wu BQ, Sun YK, Zheng J, Fang WG, Wang JL. Metastatic behavior of cultured human lung carcinoma cell lines in nude mice. In: Rygaard J, Brünner N, Græm N, Spang-Thomsen M. Immune- deficient animals in biomedical research. Proceedings of the 5 th International Workshop on Immune-deficient Animals; Copenhagen, Denmark, Oct 13-16, 1985; Karger, Basel, Switzerland; 20 May 1987; p 296-302.

16 Xia D, Li X, Lou Y, Han W, Ding P, Zhang Y, et al. Overexpression of chemokine-like factor 2 promotes the proliferation and survival of $\mathrm{CaCl}_{2}$ skeletal muscle cells. Biochim Biophys Acta 2002; 1591: 163-73.

17 Albanese C, Johnson J, Watanabe G, Eklund N, Vu D, Arnold A, et al. Transforming $\mathrm{p} 21$ ras mutants and c-Ets-2 activate the cyclin D1 promoter through distinguishable regions. J Biol Chem 1995; 270: 23 589-97.

18 Yang-Yen HF, Chambard JC, Sun YL, Smeal T, Schmidt TJ, Drouin $\mathrm{J}$, et al. Transcriptional interference between c-Jun and the glucocorticoid receptor: mutual inhibition of DNA binding due to direct protein-protein interaction. Cell 1990; 62: 1205-15.

19 Lin S, Tsai SC, Lee CC, Wang BW, Liou JY, Shyu KG. Berberine inhibits HIF-1 $\alpha$ expression via enhanced proteolysis. Mol Pharmacol 2004; 66: 612-9.

20 Jantova S, Cipak L, Letasiova S. Berberine induces apoptosis through a mitochondrial/caspase pathway in human promonocytic U937 cells. Toxicol In Vitro 2007; 21: 25-31.

21 Lin CC, Lin SY, Chung JG, Lin JP, Chen GW, Kao ST. Downregulation of cyclin $\mathrm{B} 1$ and up-regulation of wee 1 by berberine promotes entry of leukemia cells into the $\mathrm{G}_{2} / \mathrm{M}$-phase of the cell cycle. Anticancer Res 2006; 26: 1097-104.

22 Fukuda K, Hibiya Y, Mutoh M, Koshiji M, Akao S, Fujiwara H. Inhibition of activator protein 1 activity by berberine in human hepatoma cells. Planta Med 1999; 65: 381-3.

23 Mitani N, Murakami K, Yamaura T, Ikeda T, Saiki I. Inhibitory effect of berberine on the mediastinal lymph node metastasis produced by orthotopic implantation of Lewis lung carcinoma. Cancer Lett 2001; 165: 35-42.

24 Lee RJ, Albanese C, Fu M, D'Amico M, Lin B, Watanabe G, et al. Cyclin D1 is required for transformation by activated Neu and is induced through an E2F-dependent signaling pathway. Mol Cell Biol 2000; 20: 672-83.

25 Fantl V, Stamp G, Andrews A, Rosewell I, Dickson C. Mice lacking cyclin D1 are small and show defects in eye and mammary gland development. Genes Dev 1995; 9: 2364-72.

$26 \mathrm{Yu}$ Q, Geng Y, Sicinski P. Specific protection against breast cancers by cyclin D1 ablation. Nature 2001; 411: 1017-21. 